\title{
A Combined Convection Carreau-Yasuda Nanofluid Model over a Convective Heated Surface near a Stagnation Point: A Numerical Study
}

\author{
Azad Hussain, ${ }^{1}$ Aysha Rehman $\left({ }^{D},{ }^{1}\right.$ Sohail Nadeem, ${ }^{2}$ M. Y. Malik (D), ${ }^{3}$ Alibek Issakhov, ${ }^{4,5}$ \\ Lubna Sarwar, ${ }^{1}$ and Shafiq Hussain ${ }^{6}$ \\ ${ }^{1}$ Department of Mathematics, University of Gujrat, Gujrat 50700, Pakistan \\ ${ }^{2}$ Department of Mathematics, Quaid-I-Azam University, Islamabad 44000, Pakistan \\ ${ }^{3}$ Department of Mathematics, College of Sciences, King Khalid University, Abha 61413, Saudi Arabia \\ ${ }^{4}$ Department of Mathematical and Computer Modeling, Al-Farabi Kazakh National University, Almaty, Kazakhstan \\ ${ }^{5}$ Department of Mathematical and Computer Modeling, Kazakh British-Technical University, Almaty, Kazakhstan \\ ${ }^{6}$ Department of Computer Science, University of Sahiwal, Sahiwal, Pakistan
}

Correspondence should be addressed to Aysha Rehman; aysharehman1986@gmail.com

Received 18 November 2020; Revised 1 March 2021; Accepted 22 March 2021; Published 5 April 2021

Academic Editor: Adrian Neagu

Copyright (C) 2021 Azad Hussain et al. This is an open access article distributed under the Creative Commons Attribution License, which permits unrestricted use, distribution, and reproduction in any medium, provided the original work is properly cited.

\begin{abstract}
The focus of this manuscript is on two-dimensional mixed convection non-Newtonian nanofluid flow near stagnation point over a stretched surface with convectively heated boundary conditions. The modeled equation representing nonlinear flow is transformed into a system of ordinary differential equations by implementing appropriate similarity transformations. The generated structure is numerically solved by applying the bvp4c method. Consequences of various involved parameters, e.g., stretching parameter, mixed convection parameter, thermophoresis parameter, Brownian movement parameter, Lewis number, Weissenberg number, Prandtl number, Biot number, buoyancy ratio parameter, mass and heat transport rates on temperature and velocity, the stretched surface, and nanoparticle concentration patterns are analyzed. Outcomes are shown graphically and displayed in tables. Velocity fluctuations are responded to by growing parameters of mixed convection and Weissenberg number. Concentration and thermal fields are also discovered for the Prandtl number. There are also flow line diagrams to analyze the behavior.
\end{abstract}

\section{Introduction}

Today, enhancement in the heat transfer mechanism using cooling fluids has become very significant in industrial applications such as machining and electronics, energy production industries, petrochemical, aeronautics, and transportation industries. The use of irreversible strength resources and the creation of environmental provisions have supported this improvement. The objective of manufacturing heat transfer devices requires reducing cost and increasing heat transfer in each surface area unit to achieve high efficiency. In recent years, technical advances have made improvements in the rheological properties of cooling fluids, and the manufacture of a steady solid-liquid suspension called nanofluid has optimized the thermal performance of industrial instruments and heat exchangers [1]. Therefore, several researchers have reported enhancement in heat transfer through nanofluids [2-21].

The combination of forced and free convection is known as mixed convection. Extensive cases of mixed-convection are characterized as internal mass forces, where the flow is determined collectively by a few external forcing systems (i.e., external power supplied to the fluid-streamlined body system). This is a distribution of fluid in a gravity domain with differing densities. The acceleration of the Earth's temperature stratified 
mass of air and water region is the realistic presentation of mixed convection that is conventionally studied in geophysics. However, in many engineering gadgets, mixed convection is found within the system of much smaller scales. This will be encapsulated on account of certain cases alluded to in channel flows. Mixed convection is often perceived in normal and traditional situations, i.e., heating or cooling of channel walls, limited velocities of a fluid flow that are characteristics of a laminar flow. Turbulent channel flows studies with considerable gravity area impacts have evolved since the 1960s after its essential use in industrial applications in nature, e.g., electronic appliances, cooling through electric fans, solar panels exposed to wind currents, atomic reactor cooled during emergency shutoff, flow in the ocean and the atmosphere, heat transmission placed in a low-velocity environment, and so on. Cesarano [22] discussed several fractional generalizations of different types, starting from the heat equation, and suggested a method useful for analytical/numerical solutions. Cesarano [23] introduced a nonconventional approach of multi-dimensional Chebyshev polynomials. Mixed convection flow was also reported by many researchers [24-30].

Commonly, fluids are categorized into two main classifications: non-Newtonian and Newtonian fluids; the main difference between Newtonian and non-Newtonian fluid is the connection between the deformation rate tensor and the extra stress tensor [31]. In a 3D free-form extrusion printing process, the rheological property plays an important role. But no rheological model was available in the open literature that could accurately consider the impacts of both the concentration of nano/microparticles and the non-Newtonian viscosity in the paste [32]. Zuo and Liu [32] introduced a fractal rheological model for $3 \mathrm{D}$ print pastes by applying a fractional derivative and it can be also used for other non-Newtonian fluids. The experimental findings are in strong agreement with the theoretical forecast, suggesting that the model is accurate and realistic. Defining the behaviors of melts and many polymer solutions, Carreau-Yasuda model was established successfully. It was accurately applicable to many experimental viscosity patterns with a wide range of shear rates [33]. Khan et al. [34] investigated the dissimilar solutions of MHD Carreau-Yasuda fluid with slip conditions flow past a rotating disk. Andrade et al. [35] presented the turbulent flow of the non-Newtonian Carreau-Yasuda fluid. Salahuddin et al. [36] examined the influence of transverse magnetic field on the squeezed twodimensional flow of a free stream past a sensor surface of an electrically conducting Carreau-Yasuda fluid. Kumar et al. [37] discussed pulsatile blood flow through the human carotid artery by applying computational fluid dynamics.

Inspired by the above research work, the ambition of the current investigation is to study the impact of mixed convection on Carreau-Yasuda stagnation point nanofluid flow over a vertical elastic surface by applying a mathematical nanofluid model introduced by Buongiorno [38]. In our point of view, the problem is new and original. The outcomes are discussed through various parameters such as the Brownian motion parameter, mixed convection parameter, thermophoresis parameter, buoyancy ratio parameter, stretching parameter, Lewis, Weissenberg, Prandtl, and Biot numbers on the mass and heat transfer.

\section{Modeling}

We inspect the incompressible, 2D, steady flow on a stagnation point attaining the stretched surface in a Carreau-Yasuda nanofluid as shown in Figure 1. Sheet is stretched with velocity $U_{w}(x)=a x$ and ambient fluid velocity is $U_{E}(x)=b x$ while the origin is fixed at $S$. It is assumed that the surface is warmed up by convection from a hot fluid at the temperature $T_{f}$ and the sheet is warmed up by convection fluid at the temperature $T_{\infty}$ which is by heat transport coefficient $h_{f}$. The surface motion will source the evolution of the boundary layer. Consider the Cartesian coordinates system; fluid flow velocity will change through $x$ and $y$ axis in a manner that the $x$-axis is taken vertically and the $y$-axis is taken horizontally.

The elemental mathematical form of Carreau-Yasuda fluid is [39]

$$
\tau=\left[\mu_{\infty}+\left(\mu_{0}-\mu_{\infty}\right)\left((1+\Gamma \dot{\gamma})^{d}\right)^{(n-1) / d}\right] A_{1},
$$

where $\Gamma$ and $d$ are Carreau-Yasuda fluid parameters, $A_{1}$ is first Rivlin Ericksen tensor, $\mu_{\infty}$ is infinite shear rate viscosity, $\mu_{0}$ is zero shear rate viscosity, $\tau$ is extra stress tensor, and $\dot{\gamma}$ is expressed as $\dot{\gamma}=\sqrt{\operatorname{tr}\left(A_{1}^{2}\right)(1 / 2)}$, in which $A_{1}=\left[(\operatorname{gradv})^{t}+\right.$ gradv]. Take into account that infinite shear rate viscosity $\mu_{\infty}=0$ and then equation (1) reduces to the form

$$
\tau=\left[\mu_{0}\left((1+\Gamma \dot{\gamma})^{d}\right)^{(n-1) / d}\right] A_{1}
$$

Under these considerations, governing equations can be written as follows:

$$
\begin{aligned}
\frac{\partial u}{\partial x}+\frac{\partial v}{\partial y}= & 0 \\
u \frac{\partial u}{\partial x}+v \frac{\partial u}{\partial y}= & U_{E} \frac{\mathrm{d} U_{E}}{\mathrm{~d} x}+v \frac{\partial^{2} u}{\partial y^{2}}+v\left[\frac{(n-1)}{d} \cdot(d+1) \Gamma^{d}\left(\frac{\partial u}{\partial y}\right)^{d} \frac{\partial^{2} u}{\partial y^{2}}\right] \\
& +g\left[\frac{(1-C) \beta \rho_{\mathrm{fm}}}{\rho_{f}}\left(T-T_{\infty}\right)-\left(\frac{\rho_{p}-\rho_{\mathrm{fm}}}{\rho_{p}}\right)\left(C-C_{\infty}\right)\right],
\end{aligned}
$$




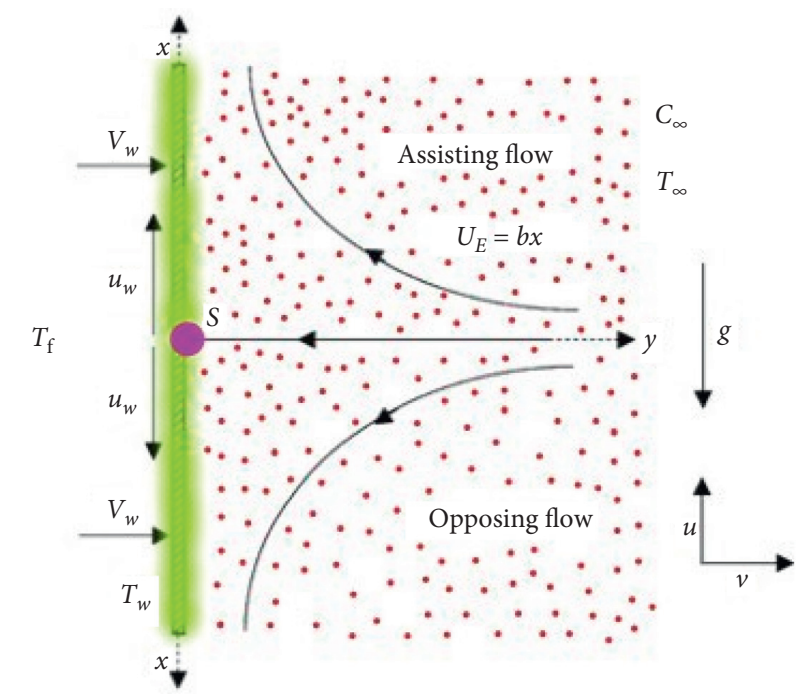

FIgURE 1: Geometry of the physical problem.

$$
\begin{aligned}
& u \frac{\partial T}{\partial x}+v \frac{\partial T}{\partial y}=\alpha \frac{\partial^{2} T}{\partial y^{2}}+\frac{\left(\rho c_{p}\right)_{p}}{\left(\rho c_{p}\right)_{f}}\left[D_{B} \frac{\partial C}{\partial y} \frac{\partial T}{\partial y}+\left(\frac{D_{T}}{T_{\infty}}\right)\left(\frac{\partial T}{\partial y}\right)^{2}\right] \\
& u \frac{\partial C}{\partial x}+v \frac{\partial C}{\partial y}=D_{B} \frac{\partial^{2} C}{\partial y^{2}}+\left(\frac{D_{T}}{T_{\infty}}\right) \frac{\partial^{2} T}{\partial y^{2}},
\end{aligned}
$$

Here, $v$ is the viscosity characteristics and $u$ and $v$ are the velocity components in the $x$ and $y$ directions, respectively, where $\left(\rho c_{p}\right)_{p} /\left(\rho c_{p}\right)_{f}$ is the proportion of nanoparticles capacity of heat to that of the base fluid capacity of heat, $\rho_{f}$ is the density of the base fluid, $\alpha=K /\left(\rho c_{p}\right)_{f}$ is the thermal diffusibility of the base fluid, $c_{p}$ is the constant pressure specific heat, $D_{B}$ is the Brownian diffusion, $D_{T}$ is the thermophoresis diffusion, and the subscripts $n p, \infty$, and $f$ denote nanoparticles, a value very far away from the solid surface, and the base fluid, respectively.

The subjected boundary conditions are defined as

$$
\begin{aligned}
u & =U_{w}(x)=a x, \\
v & =0, \\
-k \frac{\partial T}{\partial y} & =h_{f}\left(T_{f}-T\right), \\
D_{B} \frac{\partial c}{\partial y}+\left(\frac{D_{T}}{T_{\infty}}\right) \frac{\partial T}{\partial y} & =0, \quad \text { at } y \longrightarrow 0, \\
u & =U_{E}(x)=b x, \\
T & \longrightarrow T_{\infty}, \\
C & \longrightarrow C_{\infty}, \quad \text { at } y \longrightarrow \infty .
\end{aligned}
$$

Appropriate similarity transformations are defined as

$$
\begin{gathered}
\psi=\sqrt{a v} x f(\eta), \\
\eta=\sqrt{\frac{a}{v} y,} \\
u=\frac{\partial \psi}{\partial y}=a x f^{\prime}(\eta), \\
v=-\frac{\partial \psi}{\partial x}=\sqrt{a v} f(\eta), \\
\theta(\eta)=\frac{T-T_{\infty}}{T_{f}-T_{\infty}}, \\
\varphi(\eta)=\frac{C-C_{\infty}}{C_{\infty}} .
\end{gathered}
$$

Applying the above relationship, the continuity equation (3) is satisfied. Equations (4)-(6) take the following form:

$$
\begin{aligned}
{\left[1+\frac{(n-1)}{d}(d+1) W_{e}^{d}\left(f^{\prime \prime}\right)^{d}\right] f^{\prime \prime}+r^{2} } & \\
+f f^{\prime \prime}-\left(f^{\prime}\right)^{2}+\lambda \theta-N_{r} \varphi & =0, \\
\frac{1}{\operatorname{Pr}} \theta^{\prime \prime}+\theta^{\prime} f+\operatorname{Nb} \varphi^{\prime} \theta^{\prime}+\mathrm{Nt}\left(\theta^{\prime}\right)^{2} & =0, \\
\varphi^{\prime \prime}+\operatorname{LePr} f \varphi^{\prime}+\frac{\mathrm{Nt}}{\mathrm{Nb}} \theta^{\prime \prime} & =0,
\end{aligned}
$$


with boundary conditions

$$
\begin{aligned}
f & =0, \\
f^{\prime} & =1, \\
\theta^{\prime} & =-\mathrm{Bi}(1-\theta), \\
\mathrm{Nb} \varphi^{\prime}+\mathrm{Nt} \theta^{\prime} & =0, \quad \text { at } \eta \longrightarrow 0, \\
f^{\prime} & =r, \\
\theta & =0, \quad \\
\varphi & =0, \quad \text { at } \eta \longrightarrow \infty .
\end{aligned}
$$

Here, prime denotes derivation for $\eta$, and further dimensionless parameters are defined as

$$
\begin{aligned}
& \lambda=\frac{(1-c) \beta \rho_{\mathrm{fm}}\left(T_{f}-T_{\infty}\right) g}{a^{2} x \rho_{f}}, \\
& N_{r}=\frac{\left(\rho_{p}-\rho_{\mathrm{fm}}\right) c_{\mathrm{o}} g}{a^{2} x \rho_{f}} \\
& r=\frac{b}{a}, \\
& W_{e}^{d}=\left(\frac{a^{3 / 2} x \Gamma}{\sqrt{v}}\right)^{d} \text {, } \\
& \mathrm{Nt}=\frac{\left(\rho c_{p}\right)_{p} D_{T}\left(T_{f}-T_{\infty}\right)}{\left(\rho c_{p}\right)_{f} \nu T_{\infty}} \\
& \operatorname{Pr}=\frac{\nu}{\alpha}, \\
& \mathrm{Nb}=\frac{\left(\rho c_{p}\right)_{p} D_{B} C_{\infty}}{\left(\rho c_{p}\right)_{f} \nu} \\
& \mathrm{Le}=\frac{\alpha}{D_{B}}, \\
& \mathrm{Bi}=\frac{h_{f}}{k} \sqrt{\frac{\nu}{a}}, \\
& \alpha=\frac{K}{\left(\rho c_{p}\right)_{f}} \text {. }
\end{aligned}
$$

Here, $N_{r}, \lambda, \mathrm{Bi}, W_{e}$, and Le denote buoyancy ratio parameter, mixed convection parameter, Biot number, Lewis number, and Weissenberg number respectively. Pr represents the Prandtl number, $r$ is the stretching characteristic, $\mathrm{Nb}$ is the Brownian motion characteristic, and $\mathrm{Nt}$ is the thermophoresis characteristic.

The skin friction coefficient $C_{f}$, local Nusselt number $\mathrm{Nu}_{x}$, and local Sherwood number $\mathrm{Sh}_{x}$ are

$$
\begin{aligned}
C_{f} & =\frac{\tau_{w}}{\rho u_{w}^{2}}, \\
\mathrm{Nu}_{x} & =\frac{x q_{w}}{k\left(T_{f}-T_{\infty}\right)}, \\
\mathrm{Sh}_{x} & =\frac{x q_{m}}{D_{B} C_{\infty}},
\end{aligned}
$$

where $q_{w}$ presents surface heat flux, $\tau_{w}$ denotes surface shear stress, and $q_{m}$ defines surface mass flux for Carreau-Yasuda fluid as follows:

$$
\begin{aligned}
& \tau_{w}=\left[\mu\left(1+\left(\frac{n-1}{d}\right) \Gamma^{d}\left(\frac{\partial u}{\partial y}\right)^{d}\right) \frac{\partial u}{\partial y}\right]_{y=0}, \\
& q_{w}=-k\left[\frac{\partial T}{\partial y}\right]_{y=0}, \\
& q_{m}=-D_{B}\left[\frac{\partial C}{\partial y}\right]_{y=0} .
\end{aligned}
$$

By using appropriate similarity transformations (8), the expressions for dimensionless Nusselt number, skin friction, and the Sherwood number become

$$
\begin{aligned}
C_{f} \operatorname{Re}_{x}^{1 / 2} & =\left[f^{\prime \prime}(0)+\left(\frac{(n-1)}{d}\right) W_{e}^{d}\left(f^{\prime \prime}(0)\right)^{d+1}\right], \\
\mathrm{Nu}_{x} \operatorname{Re}_{x}^{-1 / 2} & =-\theta^{\prime}(0), \\
\mathrm{Sh}_{x} \operatorname{Re}_{x}^{-1 / 2} & =-\varphi^{\prime}(0) .
\end{aligned}
$$

\section{Results and Discussion}

Nonlinear differential equations (9)-(11) with boundary conditions (12) and (13) are solved by using the MATLAB program bvp4c method. These ODEs (9)-(11) with boundary conditions (12) and (13) are also solvable by Homotopy perturbation and variational iteration method $[40,41]$. For physical significance, the graphical and numerical outcomes of the solution will be taken into account. Figure 2 displays the effect of $\lambda$ on the velocity patterns $f^{\prime}(\eta)$ for distinct values of $\lambda$. It may be noticed that field of velocity increases when $(\lambda>0)$ and decreases $(\lambda<0)$. Figure 3 demonstrates the influence of $\mathrm{Nt}$ on $f^{\prime}(\eta)$. It has been observed that the velocity curveincreases while incrementing the values of Nt. The contrasting behaviour is shown for opposing flow in Figure 3. Figure 4 shows the effect of $N_{r}$ on $f^{\prime}(\eta)$, inclined value of $N_{r}$ causing the boundary layer thickness upward and downward for reverse behavior. It is revealed that the value of $n$ increases, and the flow of $f^{\prime}(\eta)$ expands. The observation is the same for opposing flow in Figure 5. Figure 6 shows that the profile of velocity increases when the values of Biot number enhancing. In general, 


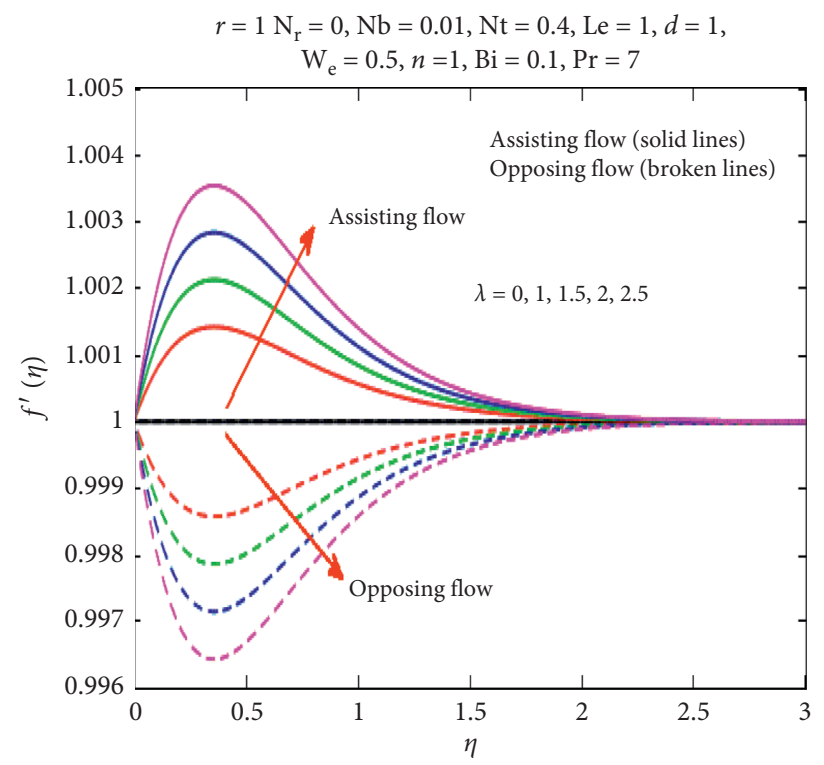

Figure 2: Outcome of $\lambda$ on $f^{\prime}(\eta)$.

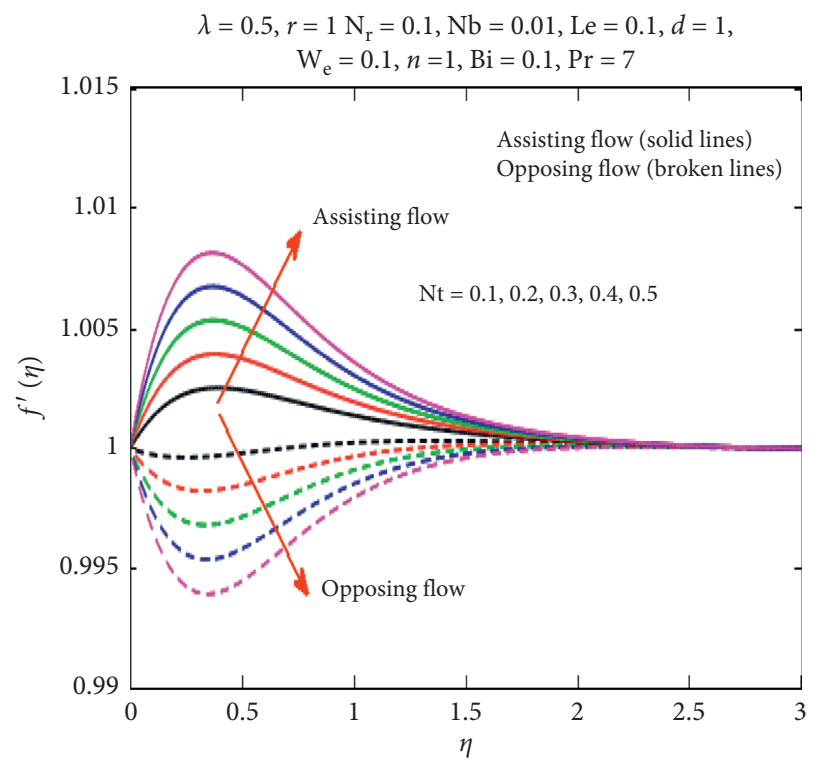

Figure 3: Variation of $\mathrm{Nt}$ on $f^{\prime}(\eta)$.

Prandtl number has an impact on $f^{\prime}(\eta)$ reversed flow for the larger value of $\operatorname{Pr}$ in Figure 7. Figure 8 show that velocity distribution of the stretching parameter increases for expanding the value of $r$. It may be noted that $W_{e}$ is enhanced, and the flow of velocity moves upward in Figure 9.

Deviation of temperature flow is discussed in Figures 10-14. Figure 10 represents the behavior of Biot number, the field of temperature inclined for a larger value of Bi. Figure 11 depicts that the larger value of the Prandtl number profile of temperature goes down rapidly. Figures 12 and 13 represent Le and $\mathrm{Nb}$, deeper presentation shown for assisting flow and upper for opposing flow on the temperature profile. Figure 14 shows the influence of the thermophoresis parameter on the thermal field; temperature flow moves downward for a larger value of $\mathrm{Nt}$.

Nanoparticle concentration field dispute is shown in Figures 15-19. Figure 15 shows that boundary layer thickness declines by increasing the values of Le, and on the other hand, boundary layer thickness inclines for opposing flow. Figure 16 describes the impact of Biot number on the concentration field. Concentration field declines by increasing the values ofBi. Figure 17 demonstrates the impact of $\operatorname{Pr}$ on $\varphi(\eta)$ field; field rises with the increment of $\operatorname{Pr}$. Figure 18 shows that concentration curve goes up for the 


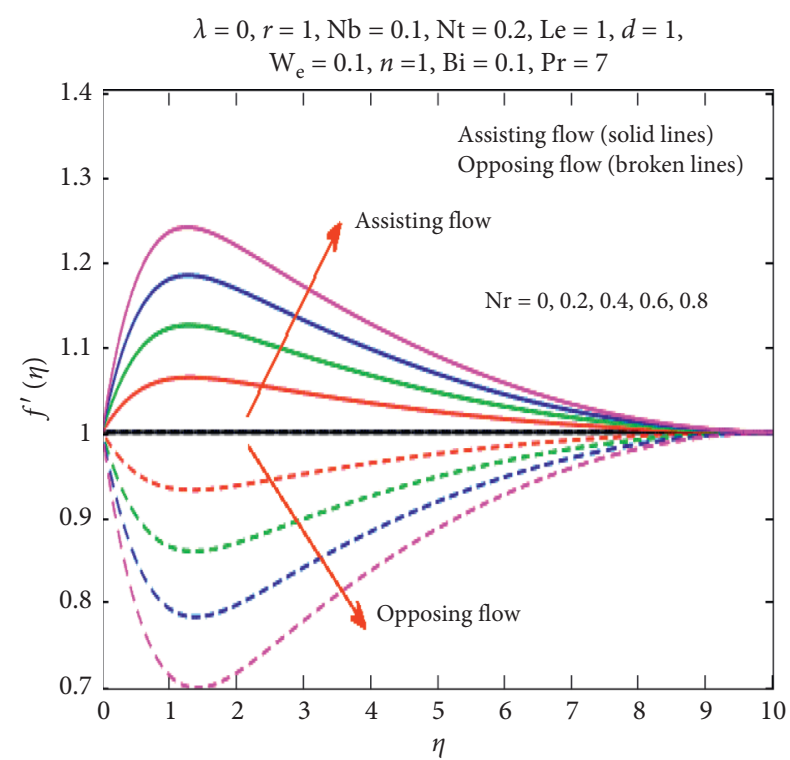

Figure 4: Impact of $\mathrm{Nr}$ on $f^{\prime}(\eta)$.

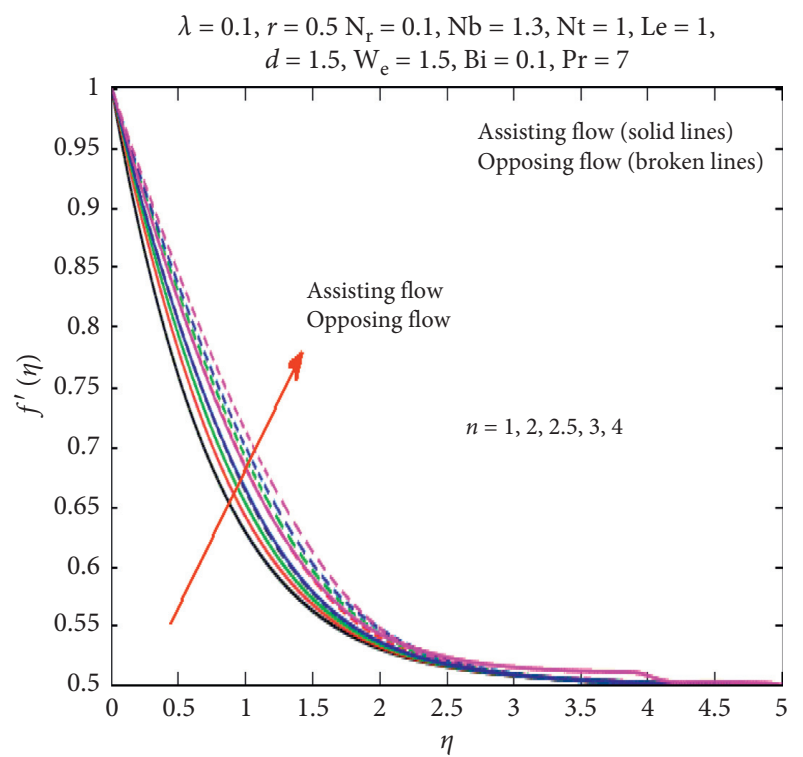

FIgURE 5: Upshot of $n$ on $f^{\prime}(\eta)$.

inclined value of $\mathrm{Nb}$ and in the reverse flow curve reduces for enlarge value of $\mathrm{Nb}$. It has been noted that in Figure 19 concentration distribution declines to expand the values of Nt. The opposite behavior is shown for opposing flow.

The results of the Nusselt number, skin friction, and Sherwood number are described numerically. Table 1 investigates the heat transfer parameter expanding if the values of $N_{r}, \mathrm{Nb}$, Le, $\mathrm{Pr}, \lambda, \mathrm{Bi}, \mathrm{Nt}$ inclined. Table 2 presents the impact of $N_{r}, \mathrm{Nb}, \mathrm{Le}, \mathrm{Pr}, \lambda, \mathrm{Bi}$, and $\mathrm{Nt}$ on the Sherwood number. The values of $\mathrm{Nb}$ increase, if the mass transfer number rapidly inclines. The numerical amount of the mass

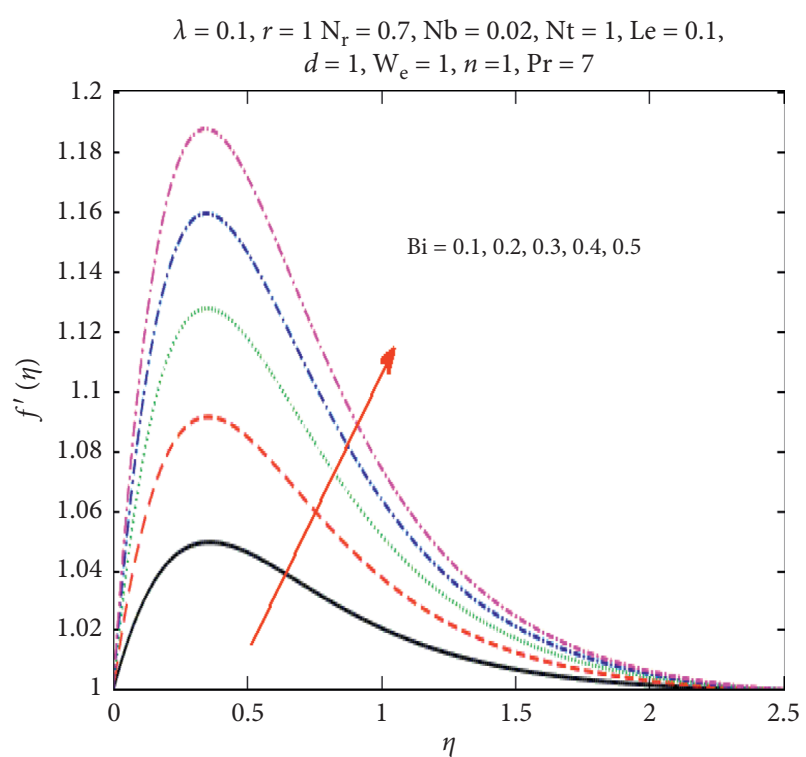

Figure 6: Result of Bi on $f^{\prime}(\eta)$.

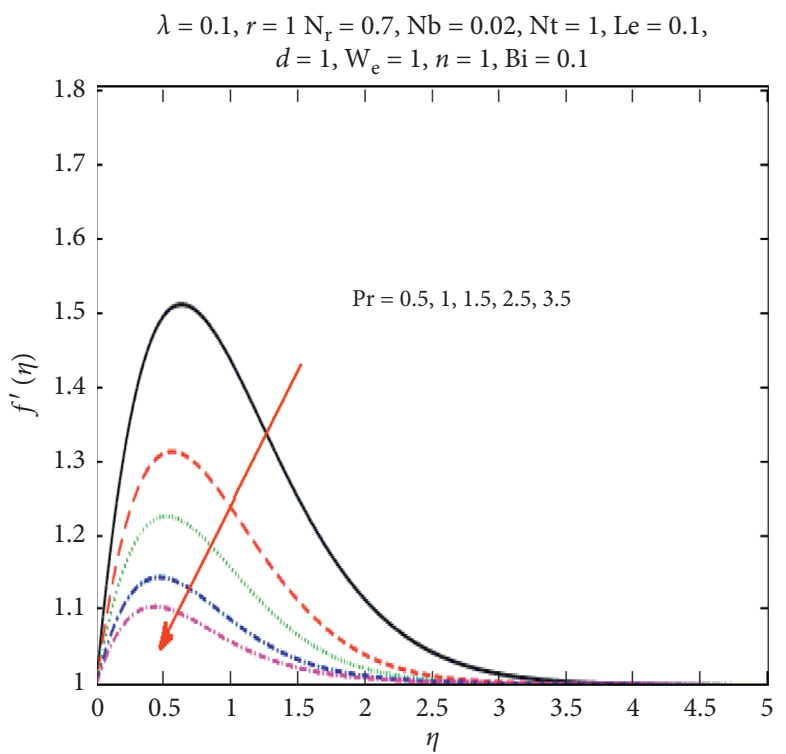

Figure 7: Effect of $\operatorname{Pr}$ on $f^{\prime}(\eta)$.

transport coefficient diminishes if the values of these parameters $N_{r}, \mathrm{Nt}, \mathrm{Le}, \mathrm{Pr}, \lambda, \mathrm{Bi}$ rise. Table 3 represents the effect of a distinct amount of the stretching parameter and other parameters on the skin friction coefficient numerically. Skin friction enlarges when the values of $N_{r}, W_{e}$, Le, and $\lambda$ increase and declines if the amount of $\mathrm{Nb}$ expands. In this paper, we cannot figure out the effect of the particle's size and distribution on the flow properties; the two-scale fractal calculus has to be adopted for this purpose [32, 42]. Furthermore, streamlines for distinct values of stretching parameter are shown in Figures 20-22, which show that fluid flows in the same direction. 


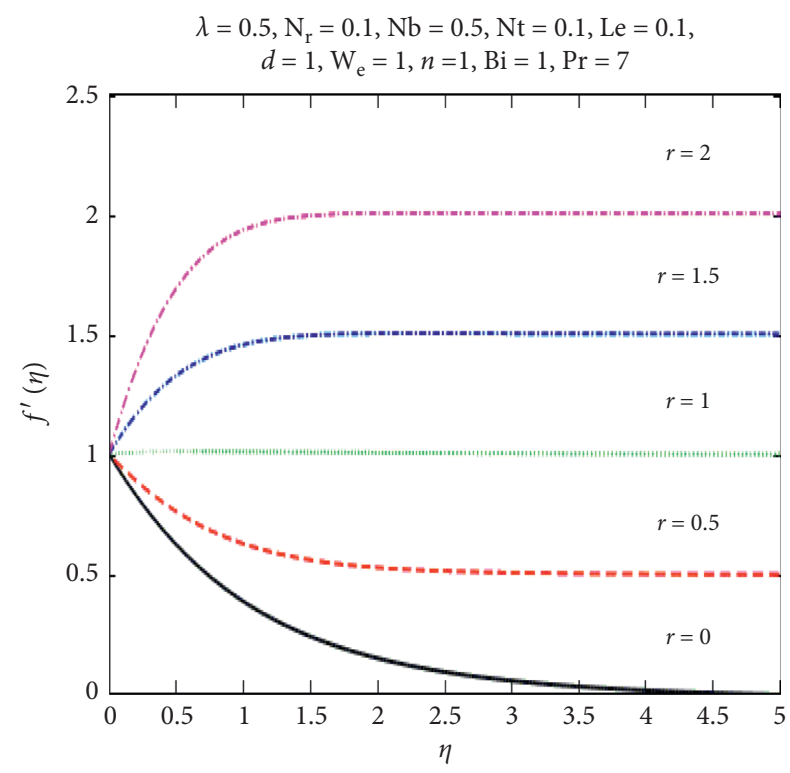

Figure 8: Consequences of $r$ on $f^{\prime}(\eta)$.

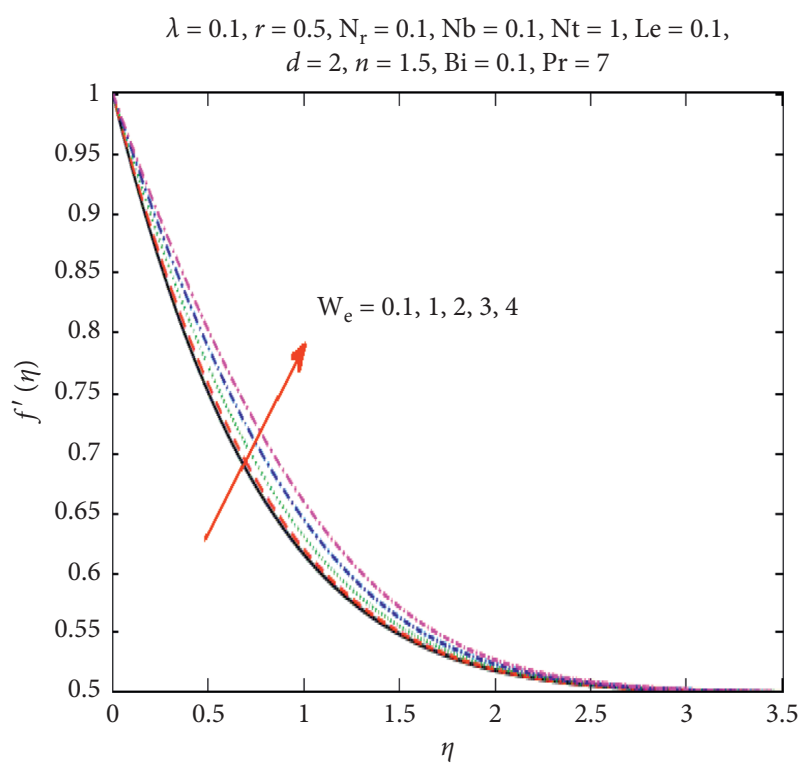

FIgURE 9: Influence of $W_{e}$ on $f^{\prime}(\eta)$.

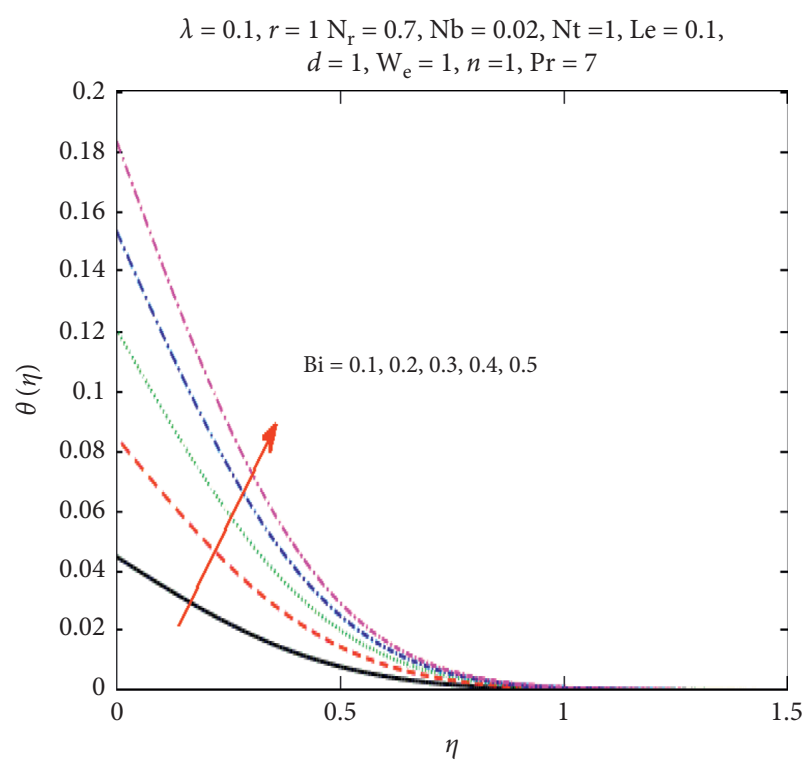

Figure 10: Upshot of $\mathrm{Bi}$ on $\theta(\eta)$.

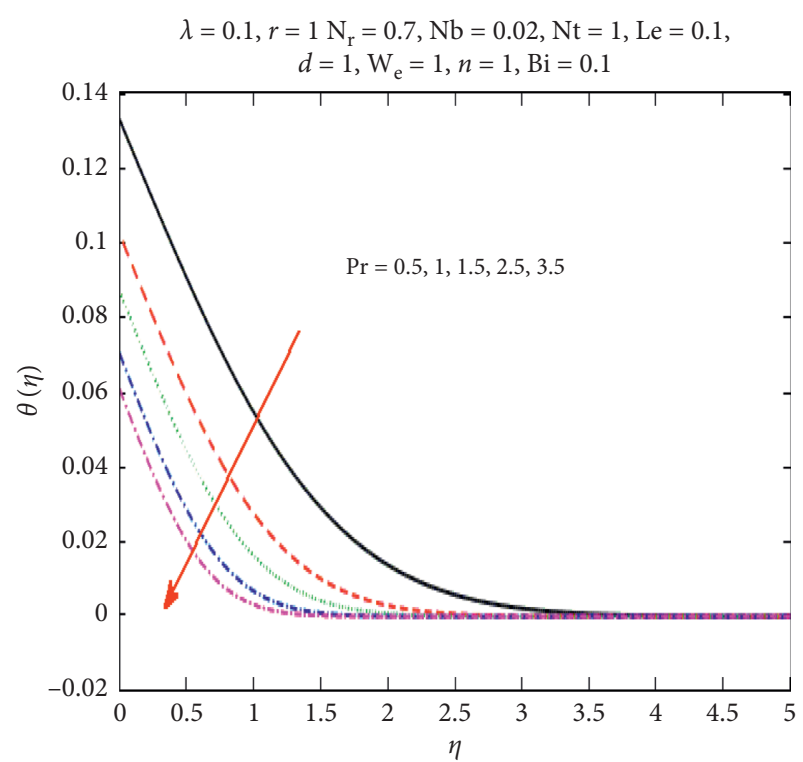

Figure 11: Result of Pr on $\theta(\eta)$. 


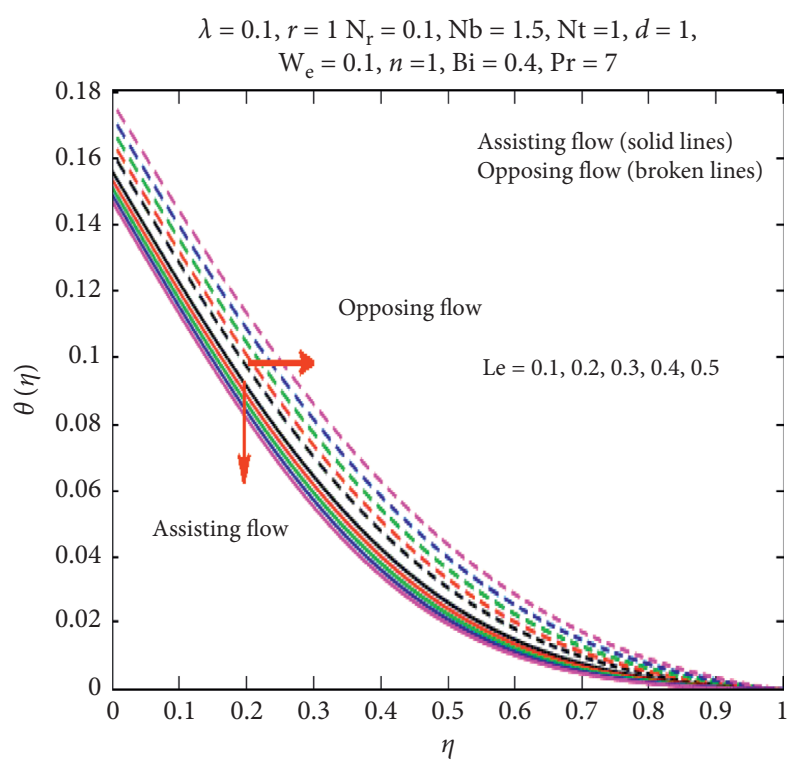

Figure 12: Upshot of Le on $\theta(\eta)$.

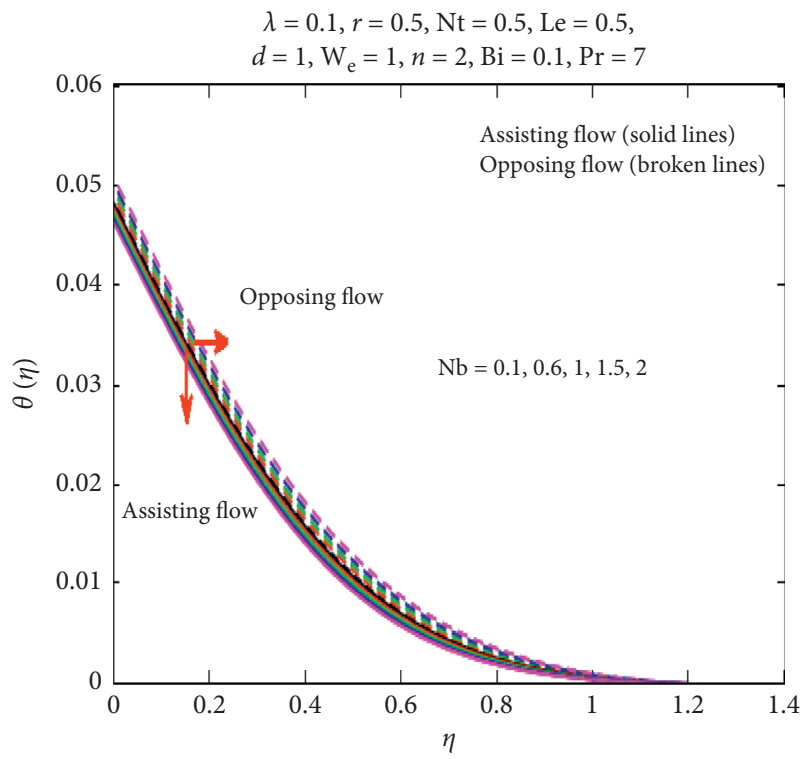

Figure 13: Influence of $\mathrm{Nb}$ on $\theta(\eta)$.

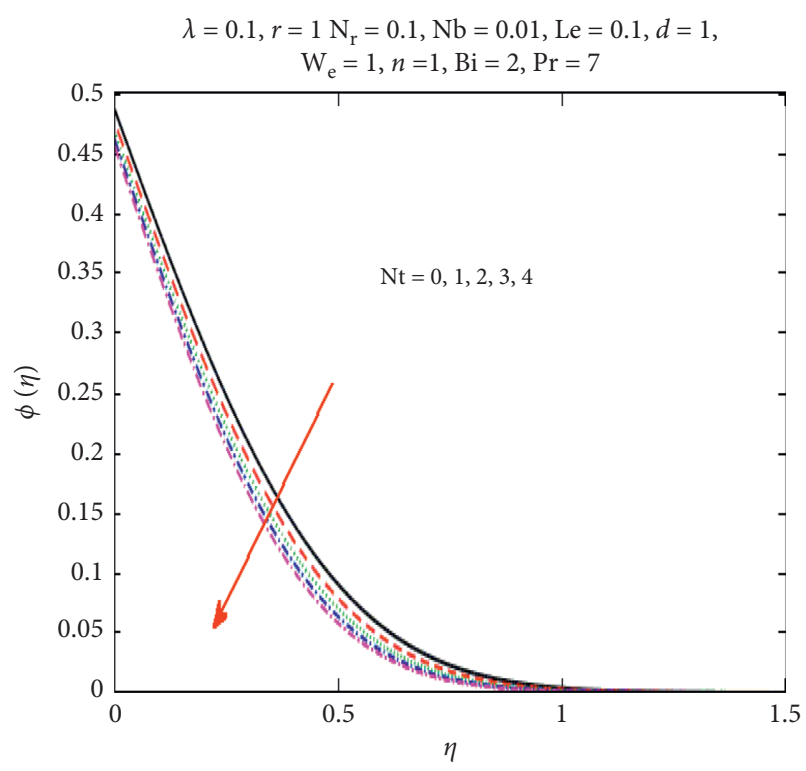

Figure 14: Deviation of Nt on $\theta(\eta)$.

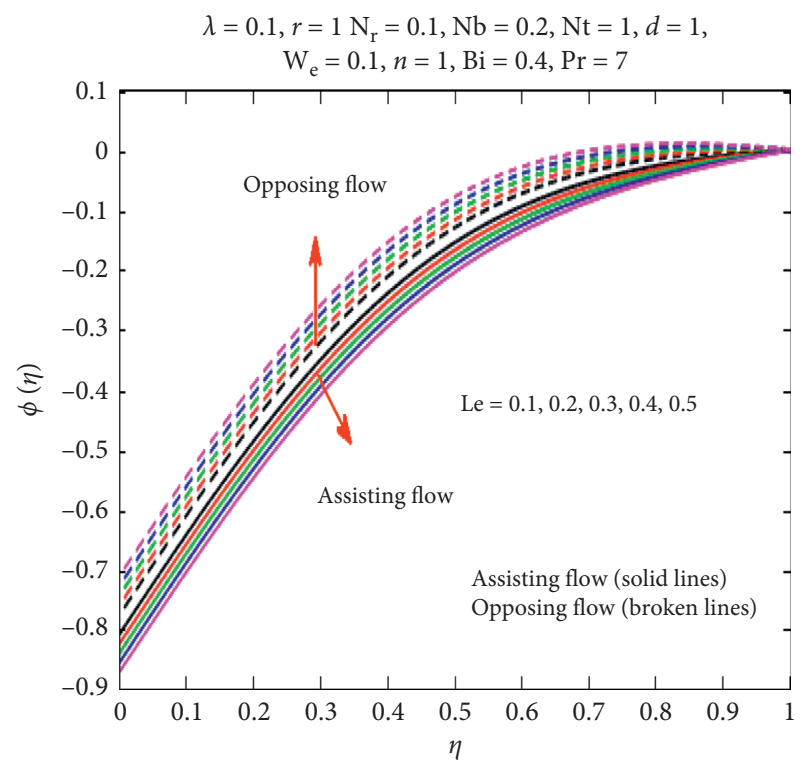

Figure 15: Impact of Le on $\varphi(\eta)$. 


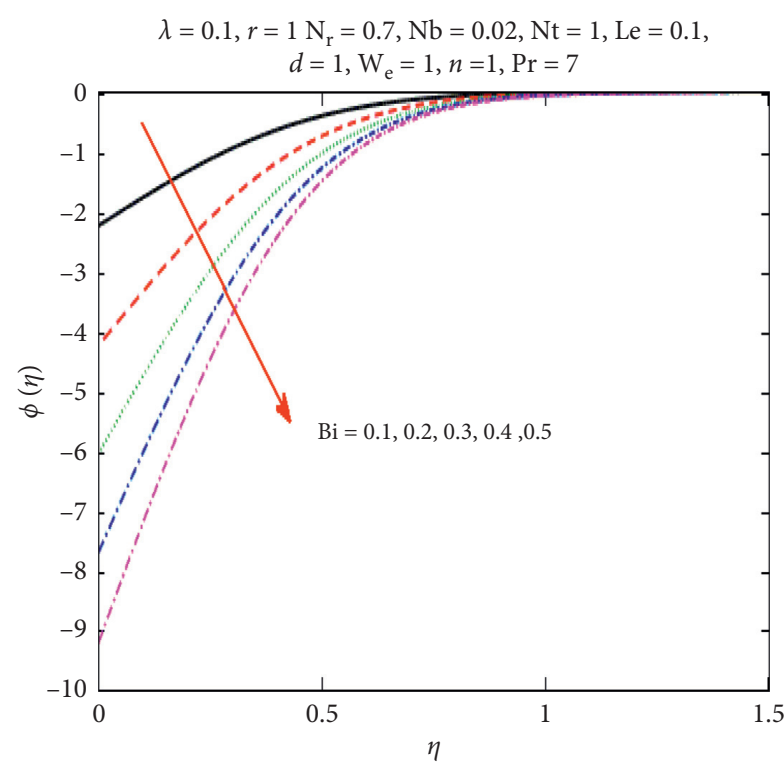

Figure 16: Effect of Bi on $\varphi(\eta)$.

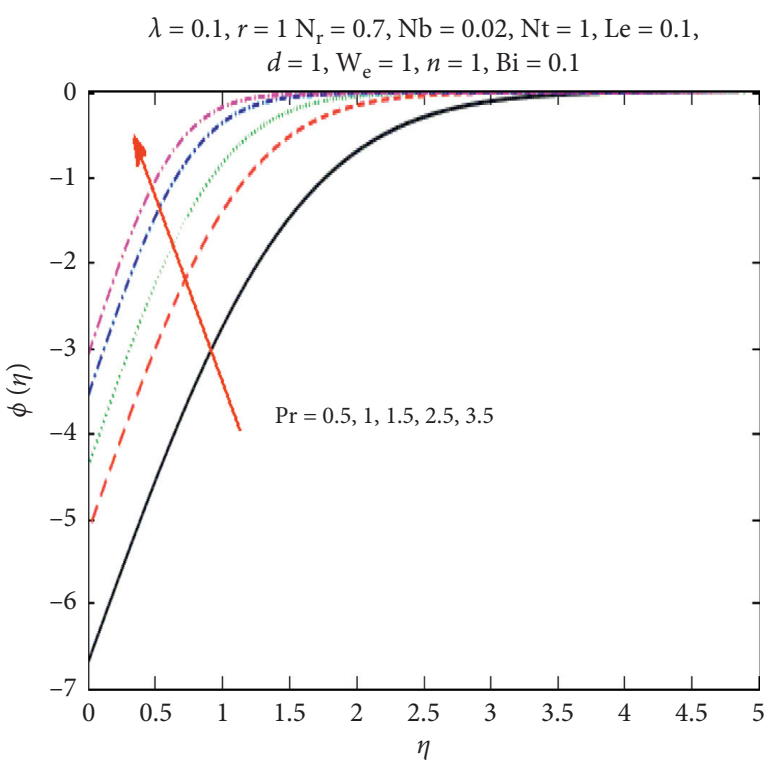

Figure 17: Result of $\operatorname{Pr}$ on $\varphi(\eta)$.

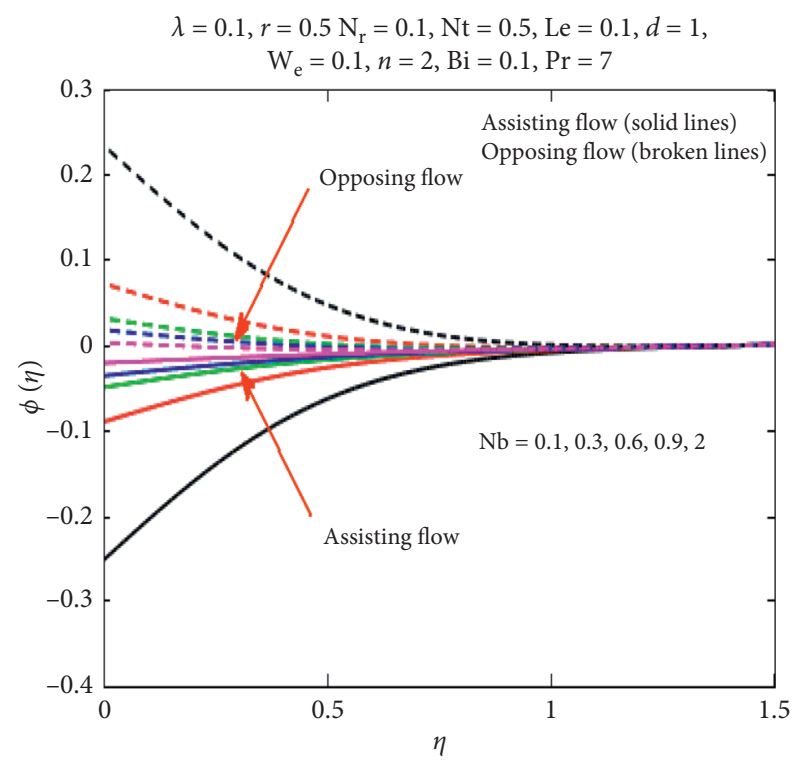

Figure 18: Consequence of $\mathrm{Nb}$ on $\varphi(\eta)$.

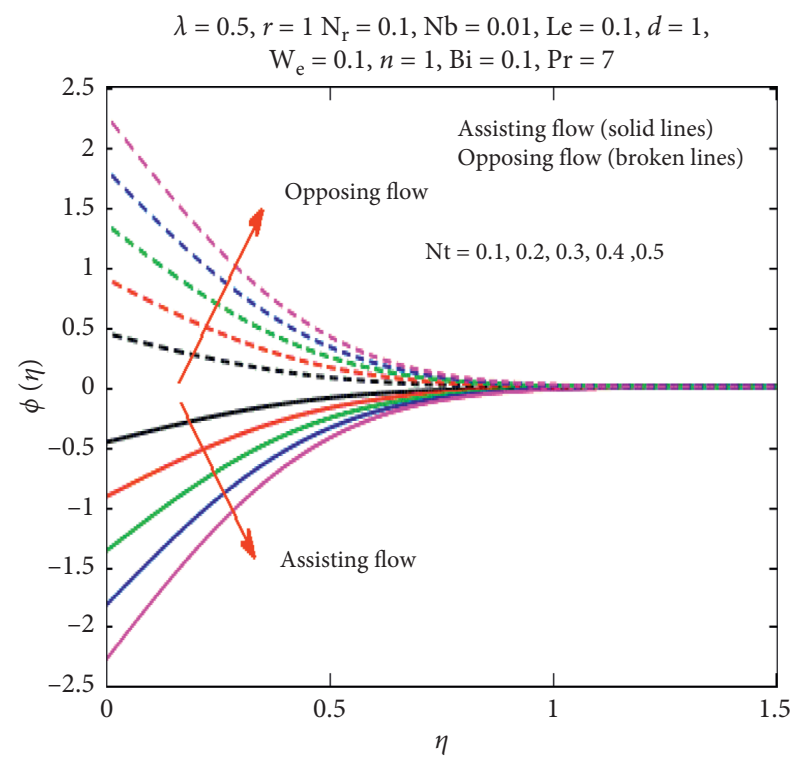

FiguRE 19: Influence of Nt on $\varphi(\eta)$. 
TABLE 1: Variation of $\mathrm{Nu}_{x}\left(\operatorname{Re}_{x}\right)^{-(1 / 2)}$ for distinct amounts of parameters.

\begin{tabular}{|c|c|c|c|c|c|c|c|c|c|c|c|c|}
\hline \multirow{2}{*}{$N_{r}$} & \multirow{2}{*}{$\mathrm{Nb}$} & \multirow{2}{*}{ Le } & \multirow{2}{*}{$d$} & \multirow{2}{*}{$n$} & \multirow{2}{*}{$\operatorname{Pr}$} & \multirow{2}{*}{$\lambda$} & \multirow{2}{*}{$W_{e}$} & \multirow{2}{*}{$\mathrm{Bi}$} & \multirow{2}{*}{$\mathrm{Nt}$} & \multicolumn{3}{|c|}{$\mathrm{Nu}_{x}\left(\mathrm{Re}_{x}\right)^{-(1 / 2)}$} \\
\hline & & & & & & & & & & $r=0.5$ & $r=1$ & $r=2$ \\
\hline 0.2 & 0.1 & 1 & 1 & 1 & 7 & 0 & 0.1 & 0.1 & 0.2 & 0.09529 & 0.09554 & 0.09600 \\
\hline 0.4 & & & & & & & & & & 0.09536 & 0.09558 & 0.09603 \\
\hline 0.6 & & & & & & & & & & 0.09541 & 0.09561 & 0.09604 \\
\hline \multirow{3}{*}{0.1} & 0.1 & 0.5 & 1 & 2 & 7 & 0.1 & 0.1 & 0.1 & 0.5 & 0.09522 & 0.09549 & 0.09596 \\
\hline & 0.6 & & & & & & & & & 0.09527 & 0.09554 & 0.09599 \\
\hline & 1 & & & & & & & & & 0.09531 & 0.09554 & 0.09602 \\
\hline \multirow{3}{*}{0.1} & 0.5 & 0.2 & 1 & 1 & 7 & 0.1 & 0.1 & 0.1 & 0.5 & 0.09522 & 0.09550 & 0.09599 \\
\hline & & 0.4 & & & & & & & & 0.09525 & 0.09552 & 0.09601 \\
\hline & & 0.6 & & & & & & & & 0.09528 & 0.09554 & 0.09602 \\
\hline \multirow{3}{*}{0.1} & 0.1 & 0.1 & 1 & 1 & 4.5 & 0.1 & 0.5 & 0.1 & 0.5 & 0.09401 & 0.09443 & 0.09511 \\
\hline & & & & & 6.5 & & & & & 0.09502 & 0.09532 & 0.09584 \\
\hline & & & & & 8.5 & & & & & 0.09565 & 0.09588 & 0.09631 \\
\hline \multirow{3}{*}{0.1} & 0.1 & 0.1 & 1 & 1 & 7 & 0.5 & 0.5 & 0.1 & 0.5 & 0.09520 & 0.09548 & 0.09598 \\
\hline & & & & & & 1 & & & & 0.09521 & 0.09548 & 0.09598 \\
\hline & & & & & & 1.5 & & & & 0.09521 & 0.09549 & 0.09599 \\
\hline \multirow{3}{*}{0.1} & 0.1 & 0.1 & 1 & 1 & 7 & 0.5 & 0.5 & 0.1 & 0.5 & 0.09520 & 0.09548 & 0.09598 \\
\hline & & & & & & & & 0.2 & & 0.18173 & 0.18273 & 0.18455 \\
\hline & & & & & & & & 0.3 & & 0.26075 & 0.26279 & 0.26655 \\
\hline \multirow{3}{*}{0.1} & 0.1 & 0.1 & 1 & 1 & 7 & 0.5 & 0.5 & 0.1 & 0.1 & 0.09520 & 0.09548 & 0.09598 \\
\hline & & & & & & & & & 0.4 & 0.09520 & 0.09548 & 0.09598 \\
\hline & & & & & & & & & 0.6 & 0.09521 & 0.09548 & 0.09598 \\
\hline
\end{tabular}

TABLE 2: Deviation of $\operatorname{Sh}_{x}\left(\operatorname{Re}_{x}\right)^{-(1 / 2)}$ for distinct values of parameters.

\begin{tabular}{|c|c|c|c|c|c|c|c|c|c|c|c|c|}
\hline \multirow{2}{*}{$N_{r}$} & \multirow{2}{*}{$\mathrm{Nb}$} & \multirow{2}{*}{ Le } & \multirow{2}{*}{$d$} & \multirow{2}{*}{$n$} & \multirow{2}{*}{ Pr } & \multirow{2}{*}{$\lambda$} & \multirow{2}{*}{$W_{e}$} & \multirow{2}{*}{$\mathrm{Bi}$} & \multirow{2}{*}{$\mathrm{Nt}$} & \multicolumn{3}{|c|}{$\mathrm{Sh}_{x}\left(\operatorname{Re}_{x}\right)^{-(1 / 2)}$} \\
\hline & & & & & & & & & & $r=0.5$ & $r=1$ & $r=2$ \\
\hline 0.2 & 0.1 & 1 & 1 & 1 & 7 & 0 & 0.1 & 0.1 & 0.2 & -0.19059 & -0.19108 & -0.19202 \\
\hline 0.4 & & & & & & & & & & -0.19072 & -0.19116 & -0.19205 \\
\hline 0.6 & & & & & & & & & & -0.19083 & -0.19123 & -0.19209 \\
\hline \multirow{3}{*}{0.1} & 0.1 & 0.5 & 1 & 2 & 7 & 0.1 & 0.1 & 0.1 & 0.5 & -0.47610 & -0.47749 & -0.47981 \\
\hline & 0.6 & & & & & & & & & -0.07939 & -0.07961 & -0.07999 \\
\hline & 1 & & & & & & & & & -0.04765 & -0.04778 & -0.04801 \\
\hline \multirow{3}{*}{0.1} & 0.5 & 0.2 & 1 & 1 & 7 & 0.1 & 0.1 & 0.1 & 0.5 & -0.09522 & -0.09550 & -0.09599 \\
\hline & & 0.4 & & & & & & & & -0.09525 & -0.09552 & -0.09601 \\
\hline & & 0.6 & & & & & & & & -0.09528 & -0.09554 & -0.09602 \\
\hline \multirow{3}{*}{0.1} & 0.1 & 0.1 & 1 & 1 & 4.5 & 0.1 & 0.5 & 0.1 & 0.5 & -0.47006 & -0.47214 & -0.47559 \\
\hline & & & & & 6.5 & & & & & -0.47511 & -0.47660 & -0.47923 \\
\hline & & & & & 8.5 & & & & & -0.47825 & -0.47941 & -0.48156 \\
\hline \multirow{3}{*}{0.1} & 0.1 & 0.1 & 1 & 1 & 7 & 0.5 & 0.5 & 0.1 & 0.5 & -0.47602 & 0.47741 & -0.47990 \\
\hline & & & & & & 1 & & & & -0.47603 & -0.47742 & -0.47991 \\
\hline & & & & & & 1.5 & & & & -0.47604 & -0.47743 & -0.47991 \\
\hline \multirow{3}{*}{0.1} & 0.1 & 0.1 & 1 & 1 & 7 & 0.5 & 0.5 & 0.1 & 0.5 & -0.47602 & -0.47741 & -0.47990 \\
\hline & & & & & & & & 0.2 & & -0.90864 & -0.91367 & -0.92278 \\
\hline & & & & & & & & 0.3 & & -1.30372 & -1.31398 & -1.33279 \\
\hline \multirow{3}{*}{0.1} & 0.1 & 0.1 & 1 & 1 & 7 & 0.5 & 0.5 & 0.1 & 0.1 & -0.09520 & -0.09548 & -0.09598 \\
\hline & & & & & & & & & 0.4 & -0.38081 & -0.38193 & -0.38392 \\
\hline & & & & & & & & & 0.6 & -0.57123 & -0.57290 & -0.57588 \\
\hline
\end{tabular}

TABLe 3: Deviation of $C_{f}\left(\operatorname{Re}_{x}\right)^{1 / 2}$ for distinct values of parameters.

\begin{tabular}{|c|c|c|c|c|c|c|c|c|c|c|c|c|}
\hline \multirow{2}{*}{$N_{r}$} & \multirow{2}{*}{$\mathrm{Nb}$} & \multirow{2}{*}{ Le } & \multirow{2}{*}{$d$} & \multirow{2}{*}{$n$} & \multirow{2}{*}{$\operatorname{Pr}$} & \multirow{2}{*}{$\lambda$} & \multirow{2}{*}{$W_{e}$} & \multirow{2}{*}{$\mathrm{Bi}$} & \multirow{2}{*}{$\mathrm{Nt}$} & \multicolumn{3}{|c|}{$C_{f}\left(\operatorname{Re}_{x}\right)^{1 / 2}$} \\
\hline & & & & & & & & & & $r=0.5$ & $r=1$ & $r=2$ \\
\hline 0.2 & 0.1 & 1 & 1 & 1 & 7 & 0 & 0.1 & 0.1 & 0.2 & -0.50648 & 0.13401 & 2.12364 \\
\hline 0.4 & & & & & & & & & & -0.35370 & 0.26517 & 2.22901 \\
\hline 0.6 & & & & & & & & & & -0.20696 & 0.39382 & 2.33364 \\
\hline
\end{tabular}


TABle 3: Continued.

\begin{tabular}{|c|c|c|c|c|c|c|c|c|c|c|c|c|}
\hline \multirow{2}{*}{$N_{r}$} & \multirow{2}{*}{$\mathrm{Nb}$} & \multirow{2}{*}{ Le } & \multirow{2}{*}{$d$} & \multirow{2}{*}{$n$} & \multirow{2}{*}{$\operatorname{Pr}$} & \multirow{2}{*}{$\lambda$} & \multirow{2}{*}{$W_{e}$} & \multirow{2}{*}{$\mathrm{Bi}$} & \multirow{2}{*}{$\mathrm{Nt}$} & \multicolumn{3}{|c|}{$C_{f}\left(\operatorname{Re}_{x}\right)^{1 / 2}$} \\
\hline & & & & & & & & & & $r=0.5$ & $r=1$ & $r=2$ \\
\hline \multirow{3}{*}{0.1} & 0.1 & 0.5 & 1 & 2 & 7 & 0.1 & 0.1 & 0.1 & 0.5 & -0.71246 & 0.04259 & 2.02497 \\
\hline & 0.6 & & & & & & & & & -0.71949 & 0.03733 & 2.02458 \\
\hline & 1 & & & & & & & & & -0.72082 & 0.03637 & 2.02499 \\
\hline \multirow{3}{*}{0.1} & 0.5 & 0.2 & 1 & 1 & 7 & 0.1 & 0.1 & 0.1 & 0.5 & -0.64893 & 0.01511 & 2.02935 \\
\hline & & 0.4 & & & & & & & & -0.63330 & 0.02797 & 2.03953 \\
\hline & & 0.6 & & & & & & & & -0.61805 & 0.04060 & 2.04956 \\
\hline \multirow{3}{*}{0} & 0.1 & 1 & 1 & 1 & 7 & 0.1 & 0.5 & 0.2 & 0.5 & -0.47006 & -0.47214 & -0.47559 \\
\hline & & & & & & 0.5 & & & & -0.47511 & -0.47660 & -0.47923 \\
\hline & & & & & & 1 & & & & -0.47825 & -0.47941 & -0.48156 \\
\hline \multirow{3}{*}{0.1} & 0.1 & 0.1 & 2 & 1.5 & 7 & 0.1 & 0.1 & 0.1 & 1 & -0.80764 & 0.02186 & 2.02357 \\
\hline & & & & & & & 0.7 & & & -0.78202 & -0.02187 & 2.02358 \\
\hline & & & & & & & 1 & & & -0.75996 & -0.02187 & 2.02358 \\
\hline
\end{tabular}

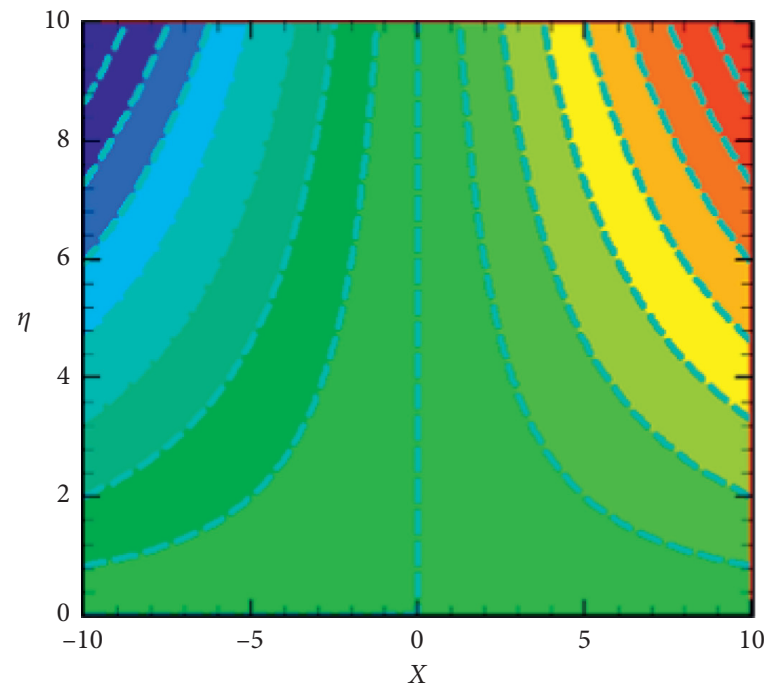

FIGURE 20: Streamlines for $r=0.5$.

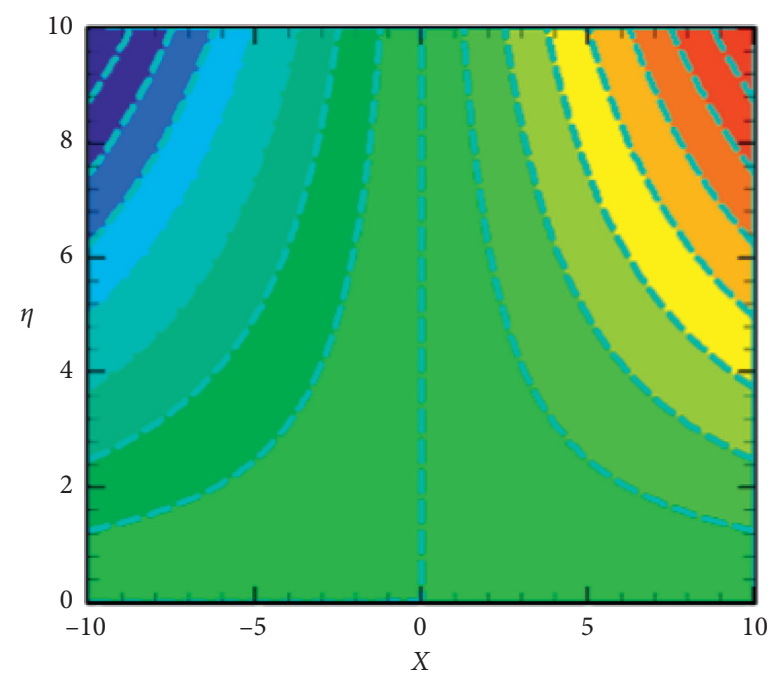

FIGURE 21: Streamlines for $r=1$. 


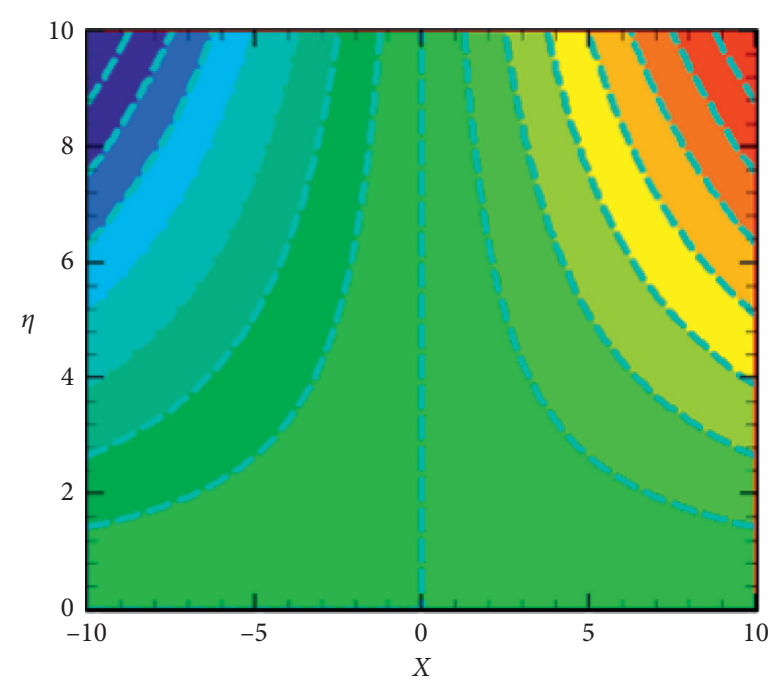

Figure 22: Streamlines for $r=2$.

\section{Concluding Remarks}

In this manuscript, the problem of combined convection Carreau-Yasuda stagnation point nanofluid flow enclosed by a stretchable surface is discussed. The problem is solved numerically by applying the bvp4c technique through MATLAB. The main findings of the highlighted results are as follows:

(i) Velocity profile accelerates by increasing the amount of $\lambda, \mathrm{Nt}, N_{r}, n, W_{e}, r, \mathrm{Bi}$ and decelerates, when decreasing the amount of Prandtl number.

(ii) It is observed that the concentration profile declined when $\mathrm{Bi}, \mathrm{Le}$, and $\mathrm{Nt}$ decreased. It is also revealed that, with the enlargement in $\mathrm{Pr}$ and $\mathrm{Nb}$, the concentration pattern expands.

(iii) The temperature profile increases with an increase in the value of Biot number (Bi) and falls when the values of $\mathrm{Pr}, \mathrm{Le}, \mathrm{Nb}$, and $\mathrm{Nt}$ increase.

(iv) Skin friction number increases when the values of $N_{r}, W_{e}$, Le, and $\lambda$ increase and fallby increasing the values of $\mathrm{Nb}$.

(v) The local Nusselt number increases, on increasing the values of $N_{r}, \mathrm{Nb}$, Le, $\mathrm{Pr}, \lambda, \mathrm{Bi}$, and $\mathrm{Nt}$.

(vi) Sherwood's number rapidly increases when the values of $\mathrm{Nb}$ shoot up. But increase in the values of $N_{r}$, Nt, Le, Pr, $\lambda$, and $\mathrm{Bi}$ then reduces the local Sherwood number.

\section{Abbreviations}

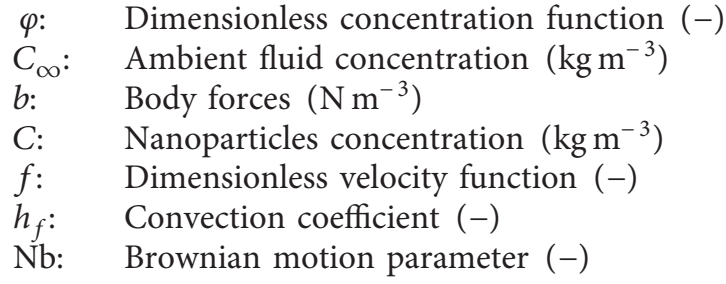

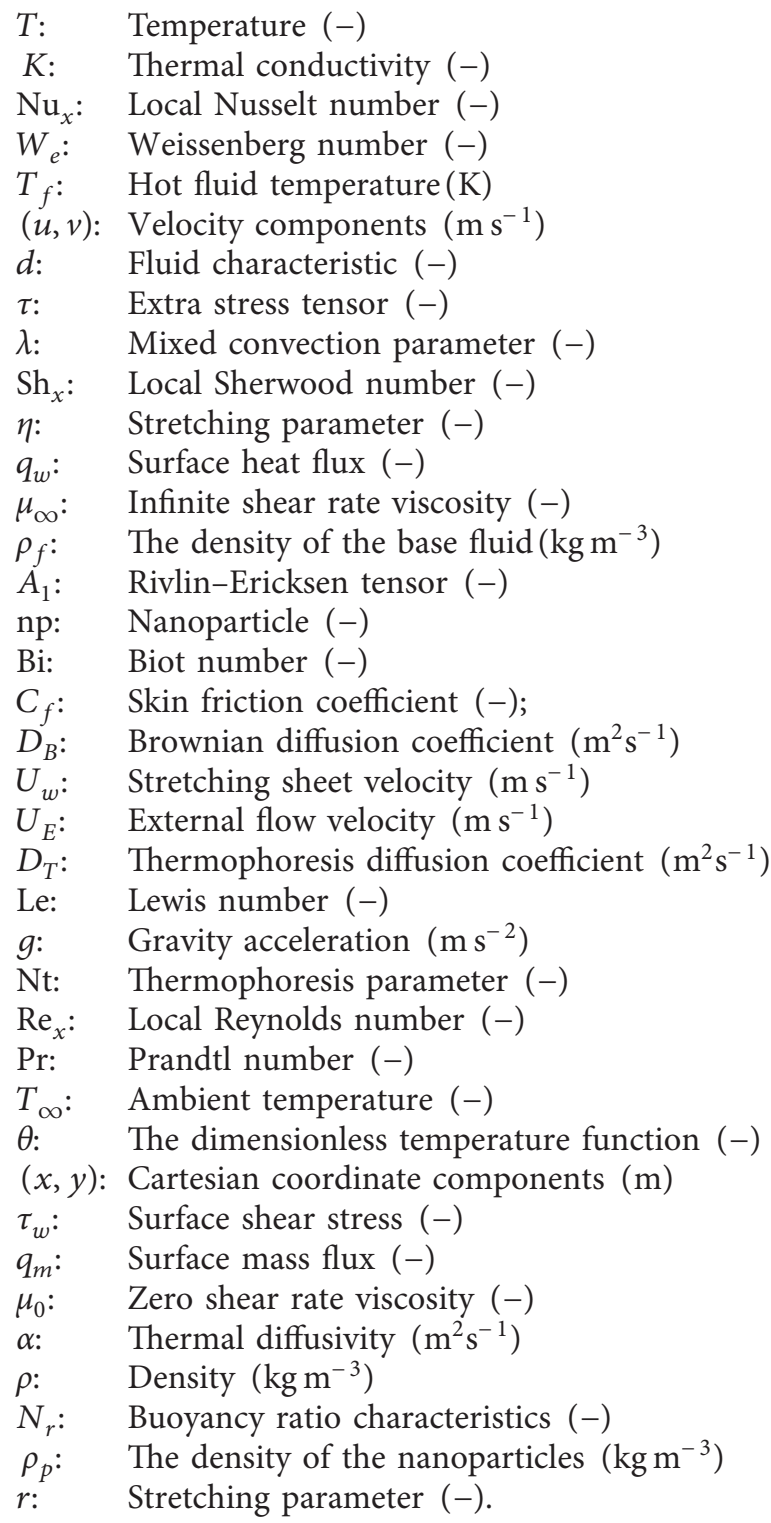




\section{Data Availability}

All data are included within this manuscript.

\section{Conflicts of Interest}

The authors declare that they have no conflicts of interest.

\section{Acknowledgments}

The authors extend their appreciation to the Deanship of Scientific Research at King Khalid University, Abha 61413, Saudi Arabia, for funding this work through research group program under grant number R. G. P-2/13/42.

\section{References}

[1] F. Talebi, A. H. Mahmoudi, and M. Shahi, "Numerical study of mixed convection flows in a square lid-driven cavity utilizing nanofluid," International Communications in Heat and Mass Transfer, vol. 37, no. 1, pp. 79-90, 2010.

[2] S. Nadeem, Z. Ahmed, and S. Saleem, "Carbon nanotubes effects in magneto nanofluid flow over a curved stretching surface with variable viscosity," Microsystem Technologies, vol. 25, no. 7, pp. 2881-2888, 2019.

[3] S. Saleem, S. Nadeem, M. M. Rashidi, and C. S. K. Raju, “An optimal analysis of radiated nanomaterial flow with viscous dissipation and heat source," Microsystem Technologies, vol. 25, no. 2, pp. 683-689, 2019.

[4] S. Nadeem and A. U. Khan, "MHD oblique stagnation point flow of nanofluid over an oscillatory stretching/shrinking sheet: existence of dual solutions," Physica Scripta, vol. 94, no. 7, Article ID 075204, 2019.

[5] T. S. Kumar and B. R. Kumar, "Effect of homogeneous-heterogeneous reactions in MHD stagnation point nanofluid flow toward a cylinder with nonuniform heat source or sink," in Applied Mathematics and Scientific Computing, pp. 287-299, Birkhäuser, Cham, Switzerland, 2019.

[6] G. Sucharitha, P. Lakshminarayana, and N. Sandeep, "MHD and cross diffusion effects on peristaltic flow of a casson nanofluid in a duct," in Applied Mathematics and Scientific Computing, pp. 191-201, Birkhauser, Cham, Switzerland, 2019.

[7] A. Ali, K. Shehzadi, M. Sulaiman, and S. Asghar, "Heat and mass transfer analysis of 3D Maxwell nanofluid over an exponentially stretching surface," Physica Scripta, vol. 94, no. 6, Article ID 065206, 2019.

[8] A. Hussain, L. Sarwar, S. Akbar, S. Nadeem, and S. Jamal, "Numerical investigation of viscoelastic nanofluid flow with radiation effects," Proceedings of the Institution of Mechanical Engineers, Part N: Journal of Nanomaterials, Nanoengineering and Nanosystems, vol. 233, pp. 2-4, 2019.

[9] M. Subhani and S. Nadeem, "Numerical analysis of micropolar hybrid nanofluid," Applied Nanoscience, vol. 9, no. 4, pp. 447-459, 2019.

[10] I. Waini, A. Ishak, and I. Pop, "Hybrid nanofluid flow and heat transfer over a nonlinear permeable stretching/shrinking surface," International Journal of Numerical Methods for Heat \& Fluid Flow, vol. 29, no. 9, pp. 3110-3127, 2019.

[11] S. Nadeem and N. Abbas, "Effects of MHD on modified nanofluid model with variable viscosity in a porous medium," Nanofluid Flow in Porous Media, 2019.

[12] F. Javed and S. Nadeem, "Numerical solution of a casson nanofluid flow and heat transfer analysis between concentric cylinders," Journal of Power Technologies, vol. 99, no. 1, pp. 25-30, 2019.

[13] A. Hussain, S. Akbar, L. Sarwar, S. Nadeem, and Z. Iqbal, "Effect of time dependent viscosity and radiation efficacy on a non-Newtonian fluid flow," Heliyon, vol. 5, no. 2, Article ID e01203, 2019.

[14] I. Waini, A. Ishak, and I. Pop, "Flow and heat transfer along a permeable stretching/shrinking curved surface in a hybrid nanofluid," Physica Scripta, vol. 94, no. 10, Article ID 105219, 2019.

[15] Z. Ahmed, S. Nadeem, S. Saleem, and R. Ellahi, "Numerical study of unsteady flow and heat transfer CNT-based MHD nanofluid with variable viscosity over a permeable shrinking surface," International Journal of Numerical Methods for Heat \& Fluid Flow, vol. 29, no. 12, pp. 4607-4623, 2019.

[16] S. Chen, M. K. Hassanzadeh-Aghdam, and R. Ansari, "An analytical model for elastic modulus calculation of $\mathrm{SiC}$ whisker-reinforced hybrid metal matrix nanocomposite containing SiC nanoparticles," Journal of Alloys and Compounds, vol. 767, pp. 632-641, 2018.

[17] X. Wang, J. Wang, X. Sun et al., "Hierarchical coral-like NiMoS nanohybrids as highly efficient bifunctional electrocatalysts for overall urea electrolysis," Nano Research, vol. 11, no. 2, pp. 988-996, 2018.

[18] A. Hussain, S. Akbar, L. Sarwar, and S. Nadeem, "Probe of radiant flow on temperature-dependent viscosity models of differential type MHD fluid," Mathematical Problems in Engineering, vol. 2020, Article ID 2927013, 16 pages, 2020.

[19] F. Hussain, A. Hussain, and S. Nadeem, "Thermophoresis and brownian model of pseudo-plastic nanofluid flow over a vertical slender cylinder," Mathematical Problems in Engineering, vol. 2020, Article ID 8428762, 10 pages, 2020.

[20] A. Rehman, A. Hussain, and S. Nadeem, "Physical aspects of convective and radiative molecular theory of liquid originated nanofluid flow in the existence of variable properties," Physica Scripta, vol. 96, no. 3, Article ID 035219, 2021.

[21] F. Mebarek-Oudina, "Convective heat transfer of Titania nanofluids of different base fluids in cylindrical annulus with discrete heat source," Heat Transfer-Asian Research, vol. 48, no. 1, pp. 135-147, 2019.

[22] C. Cesarano, "Generalized special functions in the description of fractional diffusive equations," Communications in Applied and Industrial Mathematics, vol. 10, no. 1, pp. 31-40, 2019.

[23] C. Cesarano, "Multi-dimensional Chebyshev polynomials: a non-conventional approach," Communications in Applied and Industrial Mathematics, vol. 10, no. 1, pp. 1-19, 2019.

[24] S. Ahmad and I. Pop, "Mixed convection boundary layer flow from a vertical flat plate embedded in a porous medium filled with nanofluids," International Communications in Heat and Mass Transfer, vol. 37, no. 8, pp. 987-991, 2010.

[25] A. Jamaludin, R. Nazar, and I. Pop, "Mixed convection stagnation-point flow of a nanofluid past a permeable stretching/shrinking sheet in the presence of thermal radiation and heat source/sink," Energies, vol. 12, no. 5, p. 788, 2019.

[26] H. R. Patel and R. Singh, “Thermophoresis, Brownian motion and non-linear thermal radiation effects on mixed convection MHD micropolar fluid flow due to nonlinear stretched sheet in porous medium with viscous dissipation, joule heating and convective boundary condition," International Communications in Heat and Mass Transfer, vol. 107, pp. 68-92, 2019.

[27] M. Irfan, W. A. Khan, M. Khan, and M. M. Gulzar, "Influence of Arrhenius activation energy in chemically reactive radiative flow of 3D Carreau nanofluid with nonlinear mixed 
convection," Journal of Physics and Chemistry of Solids, vol. 125, pp. 141-152, 2019.

[28] B. Golafshan and A. B. Rahimi, "Effects of radiation on mixed convection stagnation-point flow of MHD third-grade nanofluid over a vertical stretching sheet," Journal of Thermal Analysis and Calorimetry, vol. 135, no. 1, pp. 533-549, 2019.

[29] H. A. Ogunseye, P. Sibanda, and H. Mondal, "MHD mixed convective stagnation-point flow of Eyring-Powell nanofluid over stretching cylinder with thermal slip conditions," Journal of Central South University, vol. 26, no. 5, pp. 1172-1183, 2019.

[30] Y. S. Daniel, Z. A. Aziz, Z. Ismail, A. Bahar, and F. Salah, "Slip role for unsteady MHD mixed convection of nanofluid over stretching sheet with thermal radiation and electric field," Indian Journal of Physics, vol. 94, no. 2, pp. 195-207, 2019.

[31] G. R. Kefayati and H. Tang, "Three-dimensional Lattice Boltzmann simulation on thermosolutal convection and entropy generation of Carreau-Yasuda fluids," International Journal of Heat and Mass Transfer, vol. 131, pp. 346-364, 2019.

[32] Y. Zuo and H. Liu, "A fractal rheological model for sic paste using a fractal derivative," Journal of Applied and Computational Mechanics, vol. 7, no. 1, pp. 13-18, 2020.

[33] A. Pinarbasi and A. Liakopoulos, "Stability of two-layer Poiseuille flow of Carreau-Yasuda and Bingham-like fluids," Journal of Non-newtonian Fluid Mechanics, vol. 57, no. 2-3, pp. 227-241, 1995.

[34] M. Khan, T. Salahuddin, and M. Y. Malik, "Impact of enhancing diffusion on Carreau--Yasuda fluid flow over a rotating disk with slip conditions," Journal of the Brazilian Society of Mechanical Sciences and Engineering, vol. 41, no. 2, p. 78, 2019.

[35] L. C. F. Andrade, J. A. Petronílio, C. E. D. A. Maneschy, and D. O. D. A. Cruz, "The Carreau-Yasuda fluids: a skin friction equation for turbulent flow in pipes and Kolmogorov dissipative scales," Journal of the Brazilian Society of Mechanical Sciences and Engineering, vol. 29, no. 2, pp. 162-167, 2007.

[36] T. Salahuddin, M. Y. Malik, A. Hussain, S. Bilal, M. Awais, and I. Khan, "MHD squeezed flow of Carreau-Yasuda fluid over a sensor surface," Alexandria Engineering Journal, vol. 56, no. 1, pp. 27-34, 2017.

[37] N. Kumar, A. Khader, R. Pai, P. Kyriacou, S. Khan, and P. Koteshwara, "Computational fluid dynamic study on effect of Carreau-Yasuda and Newtonian blood viscosity models on hemodynamic parameters," Journal of Computational Methods in Sciences and Engineering, vol. 19, no. 2, pp. 465-477, 2019.

[38] J. Buongiorno, "Convective transport in nanofluids," Journal of Heat Transfer, vol. 128, no. 3, pp. 240-250, 2006.

[39] M. Khan, A. Shahid, M. Y. Malik, and T. Salahuddin, "Chemical reaction for Carreau-Yasuda nanofluid flow past a nonlinear stretching sheet considering Joule heating," Results in Physics, vol. 8, pp. 1124-1130, 2018.

[40] S. Jakeer and P. Bala Anki Reddy, "Entropy generation on EMHD stagnation point flow of hybrid nanofluid over a stretching sheet: Homotopy perturbation solution," Physica Scripta, vol. 95, no. 12, Article ID 125203, 2020.

[41] H. Shahmohamadi and M. M. Rashidi, "VIM solution of squeezing MHD nanofluid flow in a rotating channel with lower stretching porous surface," Advanced Powder Technology, vol. 27, no. 1, pp. 171-178, 2016.

[42] Y. Zuo, "A gecko-like fractal receptor of a three-dimensional printing technology: a fractal oscillator," Journal of Mathematical Chemistry, vol. 59, no. 3, pp. 735-744, 2021. 